\title{
Os Encontros da ANPHLAC
}

Jaime de Almeida*

Em seus 20 anos de existência, a ANPHLAC já realizou 10 Encontros, atendendo ao sexto objetivo da CONAPHLAC (25/01/1993: "Promover Encontros bianuais de pesquisadores e professores da área a nível nacional”) e ao terceiro objetivo específico da ANPHLAC, fixado pelo Documento de Mariana (15/01/1994: "Promover seminários e o intercâmbio de resultados das pesquisas realizadas, e do acervo resultante das mesmas”). As principais fontes para o estudo desses Encontros bianuais são os respectivos Anais, disponibilizados na página web da ANPHLAC. Também há algumas referências úteis na série - incompleta - do Boletim da ANPHLAC e no histórico de mensagens da lista de discussão da associação.

Examinaremos a seguinte série de Encontros:

$1^{\text {o }}$ : 28/11 a 02/12/1994 - Rio de Janeiro (organizado por Philomena Gebran)

$2^{\circ}$ : 24 a 27/07/1996 - Brasília (organizado por Jaime de Almeida)

$3^{\text {o }}$ : 22 a 24 /07/1998 - São Paulo (organizado por Maria Ligia Prado)

$4^{\circ}$ : 09 a 11/11/2000 - Salvador (organizado por Lina Maria Brandão de Aras)

$5^{\mathrm{o}}$ : 24 a 26/07/2002 - Belo Horizonte (organizado por Kátia Gerab Baggio)

$6^{\circ}$ : 20 a 23/07/2004 - Maringá (organizado por Luís Felipe Viel Moreira)

$7^{\circ}$ : 10 a 13/10/2006 - Campinas (organizado por José Alves de Freitas Neto)

$8^{\text {o }}$ : 29/07 a 01/08/2008 - Vitória (organizado por Antônio Carlos Amador Gil)

$9^{\text {o }}$ : 26 a $29 / 07 / 2010$ - Goiânia (organizado por Fabiana de Souza Fredrigo)

A informação coletada até agora apresenta algumas lacunas que dificultam o tratamento estatístico da série. Apresentaremos inicialmente uma síntese dos dados relativos a cada um dos eventos:

1 - Conforme decisão do Encontro de Mariana, o primeiro encontro da ANPHLAC (Rio de Janeiro, 1994) incorporou-se à comemoração internacional do centenário do

\footnotetext{
*Professor Associado da Universidade de Brasília (UnB). E-mail: jaimeida@terra.com.br 
intelectual peruano José Carlos Mariátegui. O evento, denominado Política e Cultura na América Latina: os Cem Anos de Nascimento de José Carlos Mariátegui, contou com a participação de um bom número de pesquisadores hispano-americanos. Pela exiguidade de tempo para sua organização, bem como pela época em que se realizou, foi reduzida a participação de pesquisadores brasileiros. Não foram publicados Anais, mas alguns dos papers apresentados foram publicados no Peru pela editora Amauta.

2 - O segundo encontro (Brasília, 1996) teve 1 conferencista, 7 eixos temáticos e 54 comunicações. Compareceram pesquisadores da Bahia, Ceará, Distrito Federal, Goiás, Minas Gerais, Rio de Janeiro, Rio Grande do Sul, Santa Catarina, São Paulo; e ainda do México (2) e da Escócia (1). A coletânea Caminhos da História da América no Brasil: tendências e contornos de um campo historiográfico reuniu 49 papers apresentados no evento. ${ }^{1}$

3 - O terceiro encontro (São Paulo, 1998) teve dois conferencistas, 32 mesas redondas e 176 inscritos, procedentes da Bahia, Ceará, Distrito Federal, Espírito Santo, Goiás, Minas Gerais, Paraíba, Paraná, Rio de Janeiro, Rio Grande do Sul, Santa Catarina e São Paulo; e ainda da Argentina (5), Chile (2) e Uruguai (1). Foram publicados 34 papers nos Anais. ${ }^{2}$

4 - A informação contida nos Anais do quarto encontro (Salvador, 2000), que publicou 22 papers, indica a presença de pesquisadores da Bahia, Distrito Federal, Espírito Santo, Goiás, Minas Gerais, Paraná, Rio Grande do Sul, São Paulo, e da Argentina (2).

5 - O quinto encontro (Belo Horizonte, 2002) teve 2 conferencistas, 33 mesas redondas, 83 apresentações de trabalhos e 147 ouvintes. Compareceram pesquisadores da Bahia, Distrito Federal, Espírito Santo, Goiás, Minas Gerais, Paraná, Rio de Janeiro, Rio Grande do Sul, Santa Catarina, São Paulo, Argentina e Bélgica. 30 papers foram publicados nos Anais.

\footnotetext{
${ }^{1}$ Organizado por Jaime de Almeida. Brasília: ANPHLAC, 1998; ISBN 8523005234; formato aprovado pela assembleia geral da ANPHLAC de julho de 1997, em Belo Horizonte.

${ }^{2}$ Formato definido pela assembleia geral da ANPHLAC de julho de 1999, em Florianópolis.
} 
6 - O sexto encontro (Maringá, 2004) teve 2 conferencistas e 47 mesas redondas que reuniram 131 pesquisadores apresentando trabalhos e 302 ouvintes, entre os quais 98 alunos da Universidad de Asunción acompanhados por seus professores, e outros da Argentina, México e Espanha. Os Anais contêm 19 papers de pesquisadores do Paraná, Rio de Janeiro, Santa Catarina, São Paulo e Tocantins.

7 - A presença de colegas estrangeiros também foi expressiva no sétimo encontro (Campinas, 2006): Argentina, Chile, Uruguai, México, Espanha, França e Israel. Houve 3 conferências e 64 mesas redondas com 164 apresentações de trabalho, dos quais 64 foram publicados nos Anais; os estados aí representados são Bahia, Distrito Federal, Goiás, Mato Grosso, Mato Grosso do Sul, Minas Gerais, Paraná, Pernambuco, Rio de Janeiro, Rio Grande do Norte, Rio Grande do Sul, Santa Catarina e São Paulo.

8 - O oitavo encontro (Vitória, 2008) teve 3 conferências, 54 mesas redondas com 133 trabalhos apresentados e 7 mini-cursos. Foram publicados 88 papers nos Anais; os estados aí representados são: Amapá, Bahia, Distrito Federal, Espírito Santo, Minas Gerais, Paraná, Rio de Janeiro, Rio Grande do Sul, Santa Catarina, São Paulo e Tocantins. A participação estrangeira limitou-se à Argentina.

9 - Os Anais do nono encontro (Goiânia, 2010) contêm 13 papers que indicam a presença de pesquisadores do Distrito Federal, Goiás, Mato Grosso, Minas Gerais, Paraná, Rio de Janeiro, Santa Catarina, São Paulo, e da Espanha. 


\begin{tabular}{|c|c|c|c|c|c|c|c|c|c|}
\hline Ano & 1994 & 1996 & 1998 & 2000 & 2002 & 2004 & 2006 & 2008 & 2010 \\
\hline Local & Rio & Brasília & São Paulo & Salvador & $\begin{array}{l}\text { Belo } \\
\text { Horizonte }\end{array}$ & Maringá & Campinas & Vitória & Goiânia \\
\hline Época & $\begin{array}{l}\text { nov- } \\
\text { dez. }\end{array}$ & julho & Julho & novembro & julho & Outubro & julho & julho & julho \\
\hline $\begin{array}{l}\text { Papers } \\
\text { apresentados }\end{array}$ & & 54 & & & 83 & 131 & 164 & 133 & \\
\hline $\begin{array}{l}\text { Papers } \\
\text { publicados }\end{array}$ & & 49 & 34 & 22 & 30 & 19 & 64 & 88 & 13 \\
\hline $\begin{array}{l}\text { Participantes } \\
\text { inscritos }\end{array}$ & & & 176 & & 230 & 433 & & & \\
\hline $\begin{array}{l}\text { Instituições } \\
\text { apoiadoras }\end{array}$ & $\begin{array}{l}\text { UERJ } \\
\text { CNPq }\end{array}$ & $\begin{array}{l}\text { UnB } \\
\text { CNPq }\end{array}$ & $\begin{array}{l}\text { USP } \\
\text { FAPESP } \\
\text { CNPq } \\
\text { Humanitas }\end{array}$ & & $\begin{array}{l}\text { UFMG } \\
\text { CAPES } \\
\text { FAPEMIG }\end{array}$ & $\begin{array}{l}\text { UEM } \\
\text { CNPq } \\
\text { CAPES } \\
\text { Prefeitura } \\
\text { Municipal } \\
\text { Museo } \\
\text { Andrés } \\
\text { Barbero }\end{array}$ & $\begin{array}{l}\text { PUC- } \\
\text { Campinas } \\
\text { CAPES } \\
\text { FAPESP }\end{array}$ & $\begin{array}{l}\text { UFES } \\
\text { CNPq } \\
\text { CAPES } \\
\text { FAPES } \\
\text { FACITEC }\end{array}$ & $\begin{array}{l}\text { UFG } \\
\text { CNPq }\end{array}$ \\
\hline
\end{tabular}


Nossa principal intenção, com este quadro, é despertar o interesse em completar e revisar os dados aqui resumidos, para melhor preservar e transmitir às próximas gerações de pesquisadores e leitores esses 'lugares de memória' da ANPHLAC que são os seus Encontros. ${ }^{3}$

Apesar das lacunas, a tabela permite visualizar algumas tendências e fazer algumas considerações:

1- Os Encontros se concentram nitidamente na região Centro-Sul do país (a única exceção ocorreu no ano 2000) e em cidades capitais. Mas os eventos de Maringá e Campinas mostram que uma boa estrutura universitária (local e regional) e a diversificação de instituições apoiadoras são condições suficientes para bons resultados.

2- A época mais apropriada é o mês de julho (férias escolares); os Encontros realizados fora desta época tendem a ser menos concorridos. É preciso, no entanto, levar em conta os dados expressivos do Encontro de Campinas, realizado em outubro, aproveitando um feriado de quinta feira.

3- O número de trabalhos apresentados nos Encontros tende a crescer, atestando a vitalidade da ANPHLAC e o desenvolvimento da produção acadêmica brasileira área de História da América.

4- A curva do número de papers publicados nos Anais da ANPHLAC não acompanha regularmente a curva do número de trabalhos apresentados nos Encontros. Neste quesito, o impacto das lacunas dos registros é mais significativo. É provável que muitos pesquisadores prefiram divulgar seus trabalhos em outras publicações que têm sido mais valorizadas pela CAPES na avaliação trienal dos programas de pós-graduação. Se isto for verdadeiro, os Anais da ANPHLAC seriam um excelente veículo de divulgação dos papers de alunos de pós-graduação.

\footnotetext{
${ }^{3}$ Muito conveniente seria, também, reconstituir a série de reuniões (algumas delas, muito bem estruturadas) e assembleias que se fazem a cada 2 anos nos simpósios nacionais da ANPUH. 
5- A presença de pesquisadores americanistas que atuam nas regiões Norte e Nordeste é pouco expressiva em nossos arquivos. Os próximos Encontros da ANPHLAC poderiam contribuir para a superação desse desequilíbrio. 